Çukurova Üniversitesi Mühendislik Mimarlık Fakültesi Dergisi, 33(2), ss. 247-260, Haziran 2018

Çukurova University Journal of the Faculty of Engineering and Architecture, 33(2), pp. 247-260, June 2018

\title{
Betonun Elastisite Modülünün Agrega/Kayaç Özelliklerinden Tahmini
}

\author{
Ahmet TEYMEN*1 \\ ${ }^{1}$ Niğde Ömer Halisdemir Üniversitesi, Mühendislik Fakültesi, Maden Mühendisliği Bölümü, Niğde
}

Geliş tarihi: $19.03 .2018 \quad$ Kabul tarihi: 29.06 .2018

Öz

Bu çalışma, agrega malzemelerinin sağlam kayaçlarının fizikomekanik özelliklerinin betonun mukavemet performansı (elastisite) üzerindeki etkisini incelemektedir. Bu amaçla çeneli kırıcı kullanılarak dokuz farklı agrega üretilmiş ve bu agregalar dokuz farklı betonun üretiminde kullanılmıştır. Betonların yapımı sırasında, su-bağlayıcı oranları, çökme ve işlenebilirlik temelinde, 0,28 ile 0,55 arasında tutulmuştur. Agrega ve kayaç özelliklerini belirlemek için toplam on yedi test yapıldı. Betonların elastisite modüllerini $\left(\mathrm{E}_{\mathrm{c}}\right)$ tahmin etmek için basit ve çoklu doğrusal regresyon analizleri (SPSS) gerçekleştirilmiş ve denklemlerin doğruluğu $\mathrm{F}$ ve t-testi ile test edilmiş̧tir. 28 günlük kür süresine göre, ilgili agrega kayaçlarının fizikomekanik özellikleri ile $\mathrm{E}_{\mathrm{c}}$ arasında güçlü korelasyonlar elde edilmiştir. Bu çalışmanın sonuçlarından \%72,2-\%98,2 aralığında değişen yüksek korelasyon katsayılı basit denklemler elde edildiğinden, $\mathrm{E}_{\mathrm{c}}$ parametresi ile kayaçların mühendislik özellikleri arasında iyi ve güvenilir ilişkiler olduğu belirlenmiştir. Ayrıca, çoklu regresyon modelleri, basit modellerden daha iyi bir tahmin verimliliğine sahiptir ve $\mathrm{E}_{\mathrm{c}}$ 'yi yeterli bir güvenirlikle tahmin etmek için uygulanabilirler.

Keywords: Agrega tipi, Elastisite modülü, Beton, Fiziksel ve mekanik özellikler

\section{Estimation of Elastic Modulus of Concrete from Aggregate/Rock Properties}

\begin{abstract}
This study examines the influence of the physico-mechanical properties of the intact rock of aggregate materials on the strength (elasticity) performance of concrete. For this aim, nine different aggregate types were produced using jaw crusher and they used in production of the nine different concretes. During the making of the concretes, water-binder ratios were kept between 0.28 and 0.55 based on the slump and workability. A total of seventeen tests were performed to determine aggregate and rock properties. Simple and multiple linear regression analyses (SPSS) were performed for estimating elastic modulus of concrete $\left(\mathrm{E}_{\mathrm{c}}\right)$ and the accuracy of equations were tested by $\mathrm{F}$ and t-test. According to 28-day curing time, strong correlations were obtained between the physicomechanical properties of the corresponding aggregate rocks and $E_{c}$. Since the simple equations with high correlation coefficient varying from $72.2 \%-98.2 \%$ were obtained from the results of this study, it is determined that there is a good and satisfactory relationship between $E_{c}$ parameter and engineering properties of rocks. Furthermore, the multiple regression models have a better predictive efficiency than simple models and they can be applied for predicting $\mathrm{E}_{\mathrm{c}}$ with reasonable confidence.
\end{abstract}

Anahtar Kelimeler: Aggregate type, Elastic modulus, Concrete, Physical and mechanical properties

*Sorumlu yazar (Corresponding author): Ahmet TEYMEN, ateymen@ohu.edu.tr 


\section{GİRIŞ}

$41 \mathrm{MPa}$ 'dan daha düşük basınç dayanımına sahip olan geleneksel beton, çimento hamuru, agregalar ve agrega/çimento hamuru ara yüzünden oluşan üç fazlı bir bileşik malzemedir. Geleneksel betonun mukavemeti, bu materyallerin niteliği ile belirlenmiştir [1]. Agrega bir betonun ana unsurudur. Betondaki agrega hacmi yaklaşık olarak \%75-80 civarındadır [2]. $\mathrm{Bu}$ nedenle, agrega özellikleri beton özelliklerde önemli rol oynamaktadır [3]. Çimento tipinin sabit olması koşuluyla, farklı özelliklere sahip betonlar farklı iri agrega türleri kullanarak elde edilebilir [4]. Geleneksel betonda, iri agrega özellikleri nadiren dayanımı sınırlayan bir parametredir. Yüksek mukavemetli agrega kullanarak yüksek dayanımlı bir beton elde etmek mümkündür. Bununla birlikte, su-çimento (w/c) oranı ve pastanın gözenek özellikleri betonun bütününe katkıda bulunmaktadır. Genellikle, bu tip beton karışımları, 0,5-0,7 arasında w/c oranı ile hazırlanır. $\mathrm{Bu} \mathrm{su}$ /çimento oranları için çimento hamuru ve agrega arasındaki bağlantı bölgesi en zayıf beton bileşenidir $[5,6]$. $\mathrm{Bu}$ durumda, agreganın önemi azdır. Yüksek mukavemetli bir beton için bu durum biraz daha farklıdır. Yüksek mukavemetli betonun nihai dayanımını kontrol eden parametreler mineralojidir ve iri agreganın mukavemet özellikleridir. Sertleştirilmiş çimento harcı ve agrega-çimento harcı arasındaki bağlantı bölgesi artık kuvvet sınırlayıcı değildir [7]. Mühendislik açısından, betonun dayanıklılık performans1, yapısal betonun en önemli ve temel özelliğidir. $\mathrm{Bu}$ nedenle, bazı araştırmacılar, agregaların beton kompozisyonu ile mekanik özellikleri arasındaki ilişkilere odaklanmıştır $[6,8,11,16,17]$. Özturan ve arkadaşları [10], iri agrega tipinin, farklı mukavemet düzeylerine sahip betonlarda basınç, eğilme ve yarmada çekme mukavemetleri üzerindeki etkisini araştırmak için bir dizi test gerçekleştirmişlerdir. Bazalt agregası ile yapılan betonun en yüksek CS'yi verdiği, çakıl ile üretilen betonun en düşük CS'yi verdiğini bildirdiler. Beshr ve arkadaşları [11] iri agregaların dört farklı betonun basınç ve eğilme mukavemeti ve elastisite modülü üzerindeki etkilerini araştırmışlardır. Bu çalışmanın sonuçları dikkate alındığında, en düşük ve en yüksek CS, sırasıyla, kalkerli kireçtaşı ve çelik cüruf agregaları ile hazırlanan beton örneklerinden elde edilmiştir.

Zhou ve arkadaşları [12] altı farklı agrega kullanarak düşük $\mathrm{w} / \mathrm{c}$ oranına sahip yüksek performanslı betonlar üretmiştir. Hem agrega kayaçlarının hem de 7, 28 ve 91 gün kür edilmiş betonların elastisite modüllerini belirlemişlerdir. Elde ettikleri sonuçlar, çok düşük ve çok yüksek elastisite modülüne sahip agregalar dişında, iyi bilinen modellerle 28 günde beton elastisite modülünün oldukça iyi bir şekilde tahmin edilebileceğini göstermiştir. Wu ve arkadaşları [13] iri agrega türün bazı beton özelliklerine etkilerini incelemek maksadıyla kuvarsit, granit, kireçtaşı ve mermer agregaları kullanmışlardır. Sonuçları, betonun mukavemet, sertlik ve kırılma enerjisinin özellikle yüksek mukavemetli beton için agrega türüne bağlı olduğunu göstermiştir. Kılıç ve arkadaşları [14] agrega türünün CS, eğilme mukavemeti ve beton aşınma direnci üzerindeki etkilerini araştırmışlardır. Araştırmacılar beş farklı agrega (gabro, bazalt, kuvarsit, kireçtaşı ve kumtaşı) kullanmışlardır. Sonuçları agrega mukavemetinin ve dokusunun betonun mukavemetini önemli derecede etkilediğini göstermiştir.

Bu çalışma, farklı fiziko-mekanik özelliklere sahip agrega kayaçlarının betonun elastisitesine etkilerini incelemek için yapılan bir dizi laboratuvar çalışmasından oluşmaktadır. Bu amaçla, dokuz farklı kayaçtan dokuz farklı agrega türü üretilmiş ve betonların üretiminde kullanılmıştır. Bu parametreler arasındaki ilişkiler belirlenmiş ve sonuçlar detaylı olarak açıklanmıştır.

\section{DENEYSEL ÇALIȘMALAR}

\subsection{Agrega Kayaçlarının Karakterizasyonu}

Agrega tipinin betonun elastisite modülüne olan etkisini araştırmak için ilgili kayaçların fiziksel ve mekanik özellikleri belirlenmiştir. Kaya örnekleri genel olarak ISRM [15] tarafindan önerilen kurallara uygun olarak hazırlanmış ve test edilmiştir. Kaya örneklerinden türetilen agregalar 
ise yine ilgili agrega standartları ve deney yöntemlerine göre test edilmiştir.

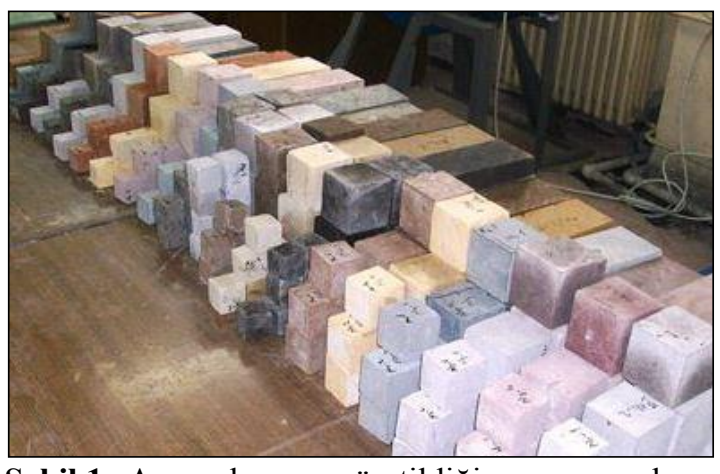

Şekil 1. Agregaların üretildiği ana kaya örneklerinin bir bölümü

Bu kapsamda ana kayaçlar için; tek eksenli basınç dayanımı $\left(\mathrm{CS}_{\mathrm{r}}\right)$, elastisite modülü $\left(\mathrm{E}_{\mathrm{r}}\right)$, eğilme dayanımı $\left(\mathrm{FTS}_{\mathrm{r}}\right)$, darbe dayanımı $\left(\mathrm{DN}_{\mathrm{r}}\right)$, Böhme aşınma dayanımı $\left(\mathrm{BSA}_{\mathrm{r}}\right), \mathrm{P}$ dalga hızı $\left(\mathrm{UPV}_{\mathrm{r}}\right)$, shore schlerescope sertlik $\left(\mathrm{SSH}_{\mathrm{r}}\right)$, brinnel sertlik
$\left(\mathrm{HB}_{\mathrm{r}}\right)$, nokta yük dayanımı $\left(\mathrm{Is}_{\mathrm{r}}\right)$, kayaç darbe katsayısı $\left(\mathrm{RIHN}_{\mathrm{r}}\right)$, birim hacim ağırlık $\left(\mathrm{UW}_{\mathrm{r}}\right)$, su emme $\left(\mathrm{WA}_{\mathrm{r}}\right)$, ve porozite $\left(\mathrm{N}_{\mathrm{r}}\right)$ testleri, agregalar için; kaya dayanım katsayısı $\left(\mathrm{CRS}_{\mathrm{r}}\right)$, yassılık indeksi $\left(\mathrm{FI}_{\mathrm{r}}\right)$, darbe dayanım indeksi (ISI $\mathrm{I}_{\mathrm{r}}$ ) ve İsveç kırılganlık deneyleri $\left(\mathrm{S}_{20 \mathrm{r}}\right)$ gerçekleştirilmiştir. Deney sonuçlarının tamamı Çizelge 1'de verilmiştir.

\subsection{Karıșım Tasarımı ve Numune Hazırlama}

Agregaların türetildiği kayaçlarının birim hacim ağırlıkları birbirinden farklı olduğu için her bir tane aralığındaki agrega miktarları hacimsel olarak sabit tutulmuştur. Benzer şekilde çimento ve kum miktarı, tüm beton karışımlarında sabit tutulmuştur. Taze betonun işlenebilirliğini ve çökmesini 8 ila $15 \mathrm{~cm}$ arasında tutabilmek için karboksilik tip süperakışkanlaştırıcı kullanılmıştır. Süper-akışkanlaştırıcı miktarı çimentonun kütlece $\% 1,2$ 'si kadardır.

Çizelge 1. Agrega kayaçlarının fiziko-mekanik özellikleri

\begin{tabular}{|l|c|c|c|c|c|c|c|c|c|}
\hline Özellikler & B & D1 & D2 & A & T1 & T2 & T3 & T4 & T5 \\
\hline $\mathrm{E}_{\mathrm{c}}(\mathrm{GPa})$ & 8,95 & 8,58 & 8,57 & 7,92 & 8,28 & 7,40 & 7,23 & 6,37 & 5,36 \\
\hline $\mathrm{CS}_{\mathrm{r}}(\mathrm{MPa})$ & 123,3 & 109,5 & 91,4 & 69,2 & 59,9 & 32,8 & 26,1 & 16,8 & 7,8 \\
\hline $\mathrm{E}_{\mathrm{r}}(\mathrm{GPa})$ & 14,15 & 13,62 & 13,19 & 7,39 & 7,82 & 3,64 & 3,84 & 3,52 & 1,72 \\
\hline FTS $_{\mathrm{r}}(\mathrm{MPa})$ & 12,29 & 11,86 & 10,85 & 6,24 & 5,50 & 3,88 & 4,82 & 3,62 & 1,23 \\
\hline $\mathrm{UPV}_{\mathrm{r}}(\mathrm{km} / \mathrm{sn})$ & 4,30 & 4,34 & 4,22 & 2,94 & 2,75 & 1,92 & 2,21 & 2,22 & 1,30 \\
\hline $\mathrm{WA}_{\mathrm{r}}(\%)$ & 0,85 & 1,21 & 1,05 & 7,42 & 6,87 & 11,91 & 16,30 & 23,05 & 25,39 \\
\hline $\mathrm{N}_{\mathrm{r}}(\%)$ & 2,29 & 3,13 & 2,71 & 14,48 & 13,89 & 20,74 & 25,79 & 33,24 & 34,43 \\
\hline $\mathrm{Is}_{\mathrm{r}}(\mathrm{MPa})$ & 9,62 & 8,37 & 6,85 & 4,69 & 3,60 & 1,90 & 2,55 & 2,17 & 1,32 \\
\hline $\mathrm{BSA}_{\mathrm{r}}\left(\mathrm{cm}{ }^{3} / 50 \mathrm{~cm}^{2}\right)$ & 13,5 & 16,3 & 15,6 & 27,2 & 28,3 & 58,5 & 57,3 & 86,4 & 122,2 \\
\hline $\mathrm{RIHN}_{\mathrm{r}}$ & 91,4 & 78,3 & 46,2 & 25,8 & 20,5 & 13,3 & 12,6 & 10,3 & 5,9 \\
\hline $\mathrm{CRS}_{\mathrm{r}}(\%)$ & 1,35 & 1,22 & 0,92 & 0,96 & 0,84 & 0,76 & 0,60 & 0,52 & 0,38 \\
\hline $\mathrm{S}_{20 \mathrm{r}}(\%)$ & 45,1 & 39,7 & 54,9 & 47,3 & 51,2 & 62,3 & 56,0 & 58,5 & 71,3 \\
\hline $\mathrm{UW}_{\mathrm{r}}\left(\mathrm{kN} / \mathrm{m}^{3}\right)$ & 26,4 & 25,4 & 25,4 & 19,3 & 19,8 & 17,1 & 15,5 & 14,4 & 13,3 \\
\hline $\mathrm{HB}_{\mathrm{r}}\left(\mathrm{kg} / \mathrm{mm}^{2}\right)$ & 194,4 & 108,5 & 115,9 & 49,2 & 32,1 & 10,9 & 12,1 & 11,5 & 3,7 \\
\hline $\mathrm{DN}_{\mathrm{r}}(\mathrm{MPa})$ & 42,0 & 31,0 & 23,0 & 17,0 & 11,8 & 8,2 & 5,9 & 5,9 & 2,0 \\
\hline $\mathrm{SSH}_{\mathrm{r}}$ & 72,0 & 68,0 & 63,0 & 54,0 & 47,0 & 34,0 & 32,0 & 22,0 & 17,0 \\
\hline $\mathrm{ISI}_{\mathrm{r}}(\%)$ & 88,1 & 86,2 & 76,8 & 73,9 & 69,1 & 55,0 & 58,8 & 56,9 & 42,0 \\
\hline $\mathrm{FI}_{\mathrm{r}}(\%)$ & 28,2 & 26,0 & 25,6 & 25,3 & 19,9 & 18,3 & 23,1 & 19,2 & 18,0 \\
\hline
\end{tabular}




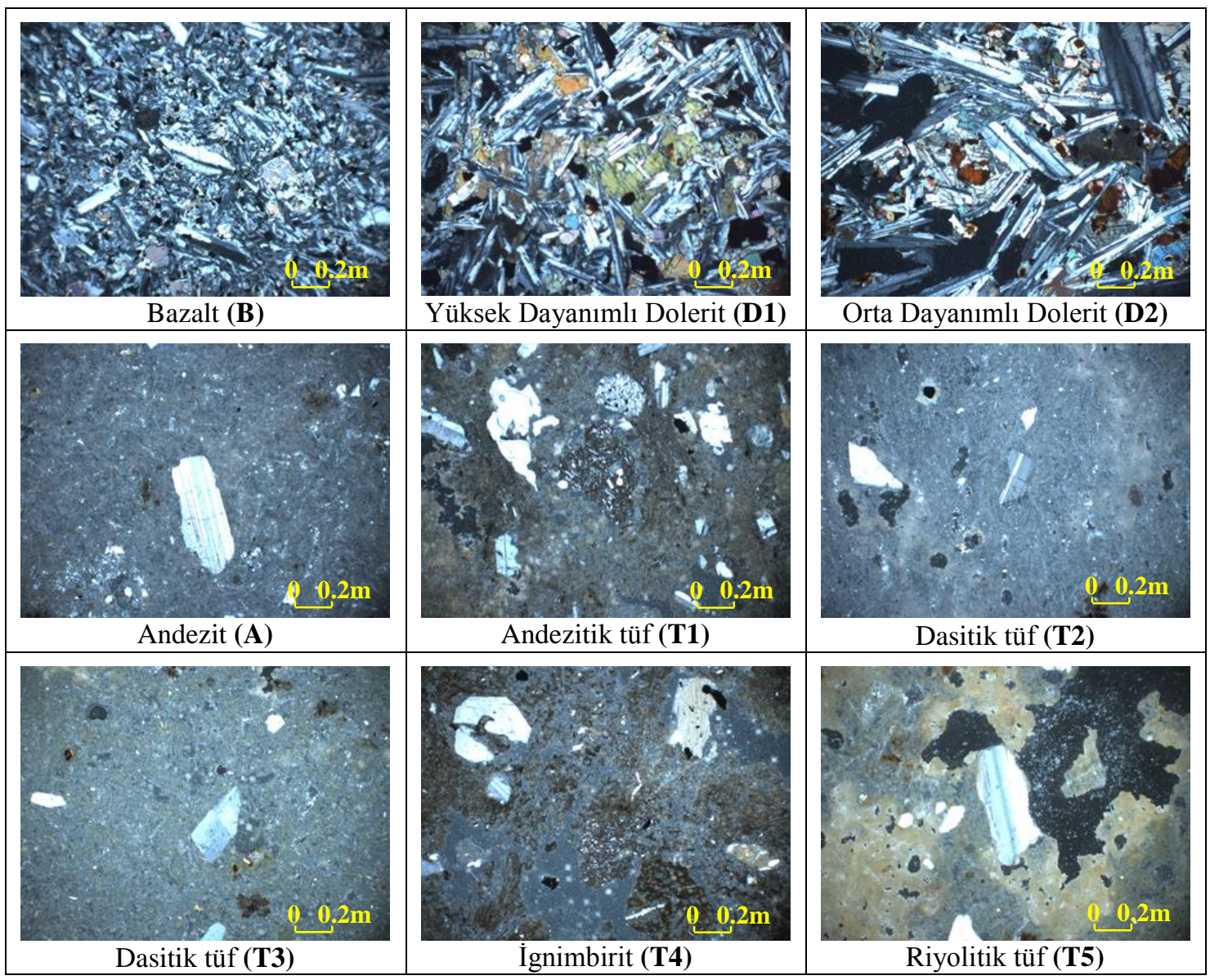

Şekil 2. Agregaların üretildiği ana kaya örneklerinin ince kesit görüntüleri

Çizelge 2. Betonların karışım kompozisyonu $\left(\mathrm{kg} / \mathrm{m}^{3}\right)$

\begin{tabular}{|l|c|c|c|c|c|c|c|c|c|}
\hline Özellikler & B & D1 & D2 & A & T1 & T2 & T3 & T4 & T5 \\
\hline İri agrega & 415 & 431 & 398 & 308 & 309 & 260 & 266 & 235 & 245 \\
\hline Orta agrega & 349 & 338 & 344 & 266 & 249 & 214 & 219 & 210 & 199 \\
\hline İnce agrega & 249 & 251 & 249 & 191 & 189 & 148 & 155 & 142 & 137 \\
\hline Kum & 735 & 735 & 735 & 735 & 735 & 735 & 735 & 735 & 735 \\
\hline Çimento & 495 & 495 & 495 & 495 & 495 & 495 & 495 & 495 & 495 \\
\hline Su & 185 & 142 & 221 & 231 & 231 & 270 & 270 & 261 & 251 \\
\hline Akışkanlaştırıc1 & 5,9 & 5,9 & 5,9 & 5,9 & 5,9 & 5,9 & 5,9 & 5,9 & 5,9 \\
\hline Taze UW & 2434 & 2396 & 2448 & 2231 & 2214 & 2126 & 2145 & 2083 & 2066 \\
\hline Kuru UW & 2275 & 2237 & 2226 & 2003 & 1973 & 1946 & 1901 & 1850 & 1836 \\
\hline
\end{tabular}

Taze beton üretimi için kullanılan agregalar yüzey kuru koşullardadır. Homojen bir beton karışımı için laboratuvar tipi beton mikseri kullanılmıştır ve her beton karışımı için üç adet, 100 mm çapında ve
$200 \mathrm{~mm}$ uzunluğunda silindirik numuneler dökülmüştür. Beton numunelerinin sıkışması için bir vibratör kullanılmıştır. Numuneler dökümden bir gün sonra kalıptan çıkarılmıştır ve 28 gün 
boyunca laboratuvar koşullarında kür edilmiştir. Beton karışımlarının bileşimleri Çizelge 2'de verilmiştir. 28 günlük kür süresinin sonunda agrega kayaçlarının fiziko-mekanik özellikleri ile arasındaki ilişkiyi saptamak üzere betonların elastisite modülleri belirlenmiştir. Mukavemet ölçümleri 3000 kN kapasiteye sahip hidrolik pres kullanılarak gerçekleştirilmiştir. Artan yükle beraber meydana gelen deformasyonlar strain gauges ve data logger yardımı ile tespit edilmiştir.

\section{3. İSTATISTIKSEL ANALIZZ}

Betonun elastisite modülünü, bileşiminin bir parçası olan agreganın fiziko-mekanik özelliklerinden tahmin etmeyi amaçlayan bu çalışmada basit ve çoklu regresyon yöntemleri kullanılmıştır. Basit regresyonlar Curve Expert, çoklu regresyonlar ise SPPS bilgisayar yazılımları yardımıyla belirlenmiştir. Elde edilen basit regresyon grafikleri Şekil 3-19'da verilmiştir. 28 günlük kür süresi sonrasında betonların Kuru birim ağırlığı $\left(\mathrm{UW}_{\mathrm{c}}\right)$ ve Young Modülü $\left(\mathrm{E}_{\mathrm{c}}\right)$ belirlenmiştir (Çizelge 1).

Curve Expert programı kullanılarak korelasyonların tespiti yapılırken iki temel unsur dikkate alınmıştır. Birincisi yüksek korelasyon katsayıs1, ikincisi ise korelasyon denkleminin sadeliğidir. Şekil 3-19 incelendiğinde en uygun ilişkiyi temsil eden ve yüksek korelasyon katsayısına sahip denklemleri elde etmek için üs, üstel, doğrusal ve logaritmik modeller ve bu fonksiyonların farklı versiyonları denenmiştir. Agrega/kayaç özelliklerinin büyük bir bölümü ile betonun elastisite modülü anlamlı korelasyonlar göstermiştir ve basit regresyon analizleri ile elde edilen basit denklemlerin korelasyon katsayıları $\left(R^{2}\right)$ 0,722 ile 0,982 arasında değişmektedir.

0,95'den büyük korelasyon kaysayılarına sahip denklemler sirasiyla; $\mathrm{UW}_{\mathrm{r}}(0,982), \mathrm{CS}_{\mathrm{r}}(0,981)$, $\mathrm{BSA}_{\mathrm{r}}(0,980), \mathrm{SSH}_{\mathrm{r}}(0,979), \mathrm{RIHN}_{\mathrm{r}}(0,962)$ ve $\mathrm{WA}_{\mathrm{r}} \quad(0,955), \quad 0,90-0,95$ aras1 korelasyon kaysayılarına sahip denklemler sırasıyla; $\mathrm{CRS}_{\mathrm{r}}$ $(0,947), \mathrm{E}_{\mathrm{r}}(0,944), \mathrm{DN}_{\mathrm{r}}(0,933), \mathrm{HB}_{\mathrm{r}}(0,922), \mathrm{N}_{\mathrm{r}}$ $(0,914)$, FTS $_{\mathrm{r}}(0,907), \mathrm{ISI}_{\mathrm{r}}(0,903), \mathrm{Is}_{\mathrm{r}}(0,896)$ ve $\begin{array}{llll}U^{\prime} & (0,869) \\ \end{array} V^{\prime}$ dir. $\quad S_{20 r} \quad 0,767$ korelasyon katsayısına sahipken, $\mathrm{FI}_{\mathrm{r}} \quad 0,722 \quad \mathrm{R}^{2}$ değerine sahiptir. Elde edilen basit korelasyon denklemleri (Eşitlik 1-17) şu şekildedir;

$\mathrm{E}_{\mathrm{c}}=\mathrm{CS}_{\mathrm{r}} /\left(0,354+0,17 \mathrm{CS}_{\mathrm{r}}^{0,91}\right)$

$E_{c}=9,56 E_{r} /\left(1,35+E_{r}\right)$

$\mathrm{E}_{\mathrm{c}}=5+1,53 \ln \left(\mathrm{FTS}_{\mathrm{r}}\right)$

$\mathrm{E}_{\mathrm{c}}=10,7 \mathrm{e}^{-0,87 / \mathrm{UPV}_{\mathrm{r}}}$

$\mathrm{E}_{\mathrm{c}}=8,7 \mathrm{WA}_{\mathrm{r}}^{-0,005 \mathrm{WA}_{\mathrm{r}}}$

$\mathrm{E}_{\mathrm{c}}=8,9 \mathrm{~N}_{\mathrm{r}}^{-0,003 \mathrm{~N}_{\mathrm{r}}}$

$E_{c}=7,16\left(I_{s}-1,26\right)^{0,1}$

$\mathrm{E}_{\mathrm{c}}=9,27 \mathrm{e}^{-\mathrm{BSA}_{\mathrm{r}} / 230}$

$\mathrm{E}_{\mathrm{c}}=8,94 /\left[1+\frac{\mathrm{RIHN}_{\mathrm{r}}}{4,52}\right]^{-1,36}$

$\mathrm{E}_{\mathrm{c}}=9,29\left(1-\mathrm{e}^{-2,32 \mathrm{CRS}_{\mathrm{r}}}\right)$

$\mathrm{E}_{\mathrm{c}}=8,95 /\left[1-\frac{\mathrm{S} 20_{\mathrm{r}}}{77}\right]^{5,5}$

$E_{c}=6,2\left(U W_{r}-13\right)^{0,134}$

$\mathrm{E}_{\mathrm{c}}=\mathrm{HB}_{\mathrm{r}} /\left(0,21+0,135 \mathrm{HB}_{\mathrm{r}}^{0,96}\right)$

$\mathrm{E}_{\mathrm{c}}=\mathrm{DN}_{\mathrm{r}} /\left(0,11+0,14 \mathrm{DN}_{\mathrm{r}}^{0,93}\right)$

$\mathrm{E}_{\mathrm{c}}=4,59\left(\mathrm{SSH}_{\mathrm{r}}-14,35\right)^{0,16}$

$\mathrm{E}_{\mathrm{c}}=13,86 \mathrm{e}^{-38,8 / \text { ISI }_{\mathrm{r}}}$

$\mathrm{E}_{\mathrm{c}}=7,3\left(\mathrm{FI}_{\mathrm{r}}-17,94\right)^{-0,062}$

Şüphesiz ayrıntılı olarak incelenmesi gereken ilişki kayaçların elastisite modülleri ile bu kayaçlardan türetilen agregalar kullanilarak elde edilen betonların elastisite modülleri arasındaki ilişkidir. Şekil 4'ten görüleceği üzere, betonların elastisite modülü değerleri ile ilgili agrega kayaçlarının elastisite modülü değerleri arasında önemli bir korelasyon olduğu bulunmuştur. 


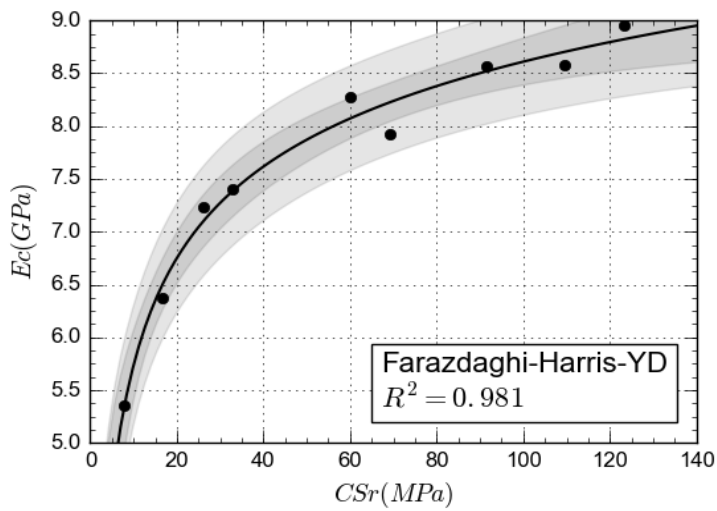

Şekil 3. Beton elastisite modülü $\left(\mathrm{E}_{\mathrm{c}}\right)$-kayaç basınç dayanımı $\left(\mathrm{CS}_{\mathrm{r}}\right)$ ilişskisi (Eşitlik 1)

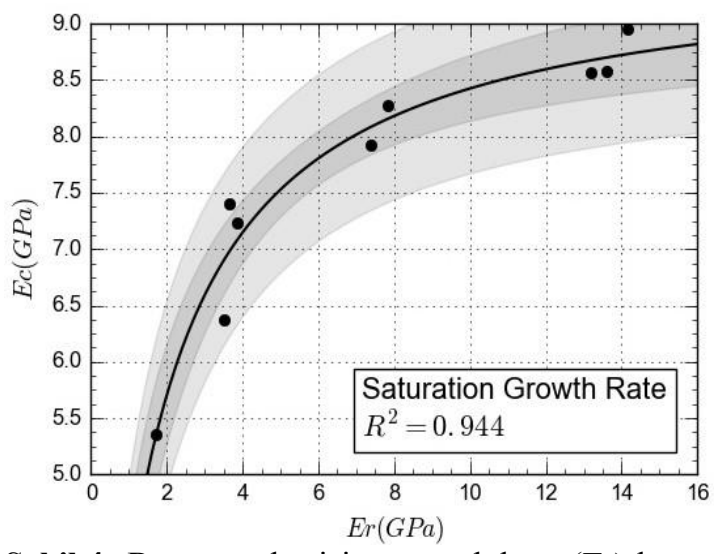

Şekil 4. Beton elastisite modülü $\left(\mathrm{E}_{\mathrm{c}}\right)$-kayaç elastisite modülü $\left(\mathrm{E}_{\mathrm{r}}\right)$ ilişkisi (Eşitlik 2)

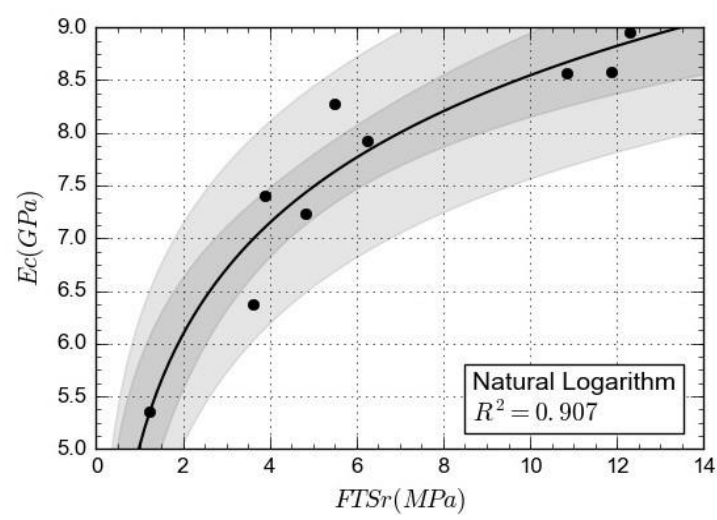

Şekil 5. Beton elastisite modülü $\left(\mathrm{E}_{\mathrm{c}}\right)$-kayaç eğilme dayanımı $\left(\mathrm{FTS}_{\mathrm{r}}\right)$ ilişkisi (Eşitlik 3)

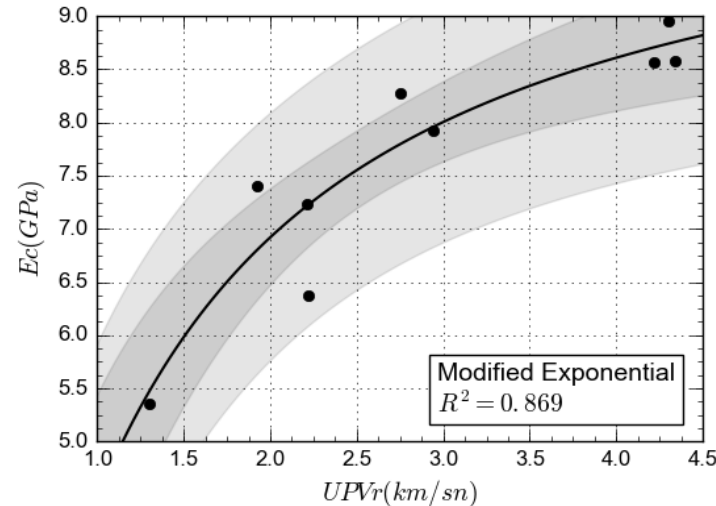

Şekil 6. Beton elastisite modülü ( $\left.\mathrm{E}_{\mathrm{c}}\right)$-kayaç Pdalga hızı $\left(\mathrm{UPV}_{\mathrm{r}}\right)$ ilişkisi (Eşitlik 4)

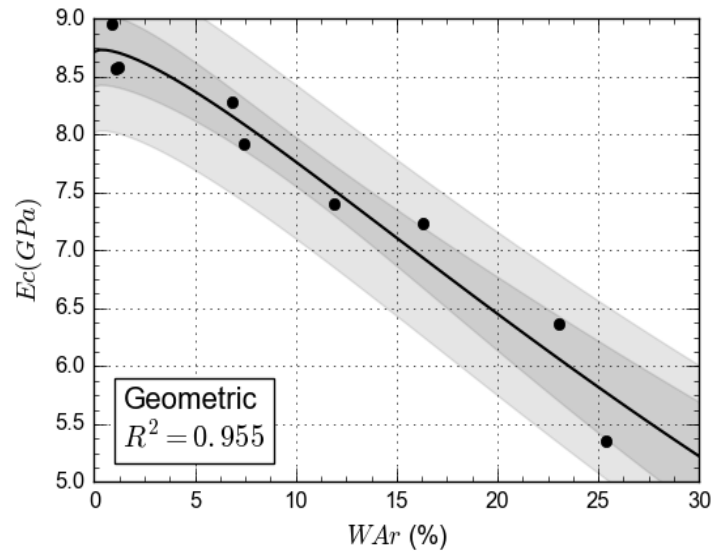

Şekil 7. Beton elastisite modülü $\left(\mathrm{E}_{\mathrm{c}}\right)$-kayaç su emme $\left(\mathrm{WA}_{\mathrm{r}}\right)$ oranı ilişkisi (Eşitlik 5)

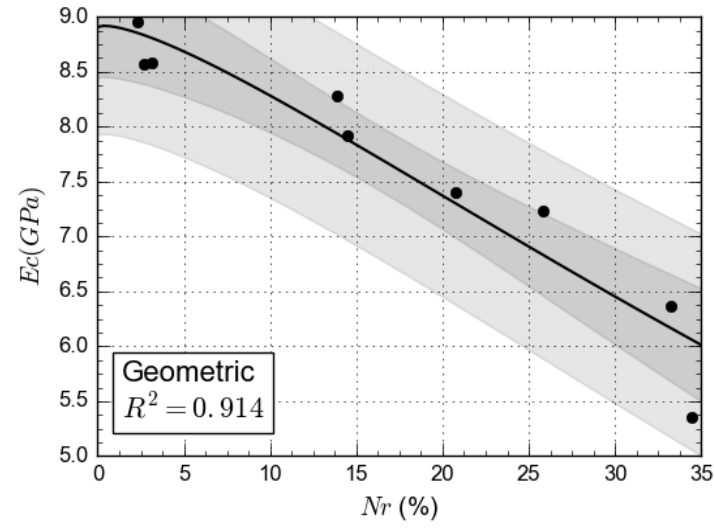

Şekil 8. Beton elastisite modülü $\left(E_{c}\right)$-kayaç porozite $\left(\mathrm{N}_{\mathrm{r}}\right)$ değeri ilişskisi (Eşitlik 6) 


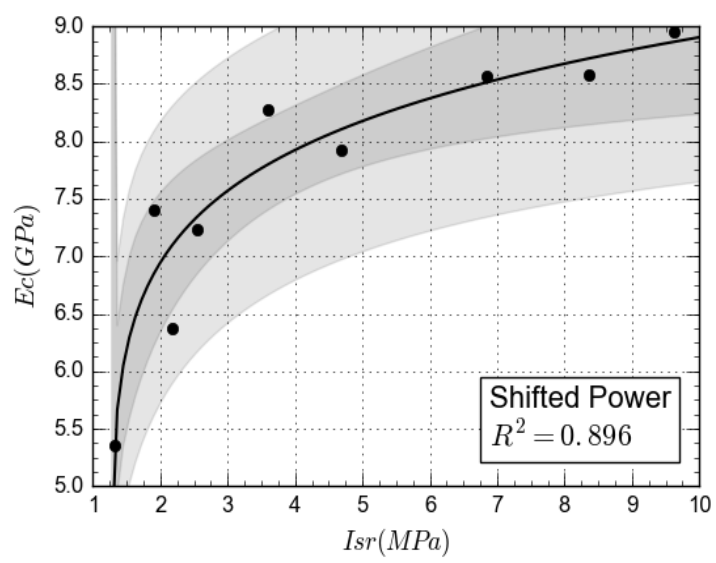

Şekil 9. Beton elastisite modülü $\left(E_{c}\right)$-kayaç nokta yük (Is $s_{r}$ dayanımı ilişkisi (Eşitlik 7)

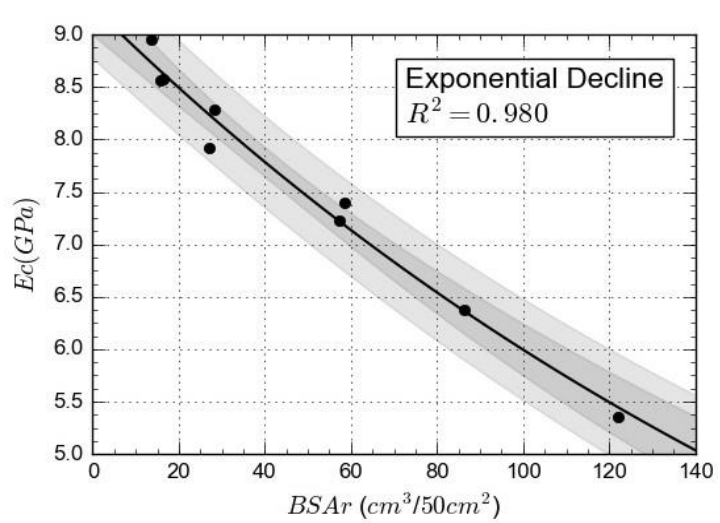

Şekil 10. Beton elastisite modülü $\left(\mathrm{E}_{\mathrm{c}}\right)$-kayaç böhme aşınması $\left(\mathrm{BSA}_{\mathrm{r}}\right)$ ilişkisi (Eşitlik 8)

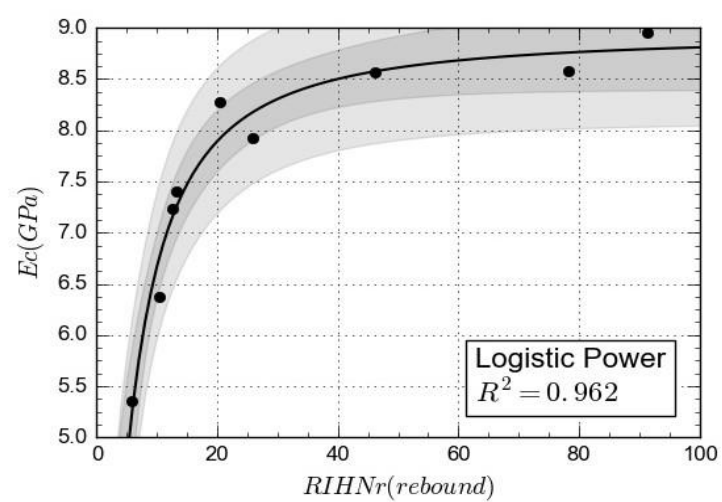

Şekil 11. Beton elastisite modülü $\left(E_{c}\right)$ - darbe sertlik numarası $\left(\mathrm{RIHN}_{\mathrm{r}}\right)$ ilişkisi (Eşitlik 9)

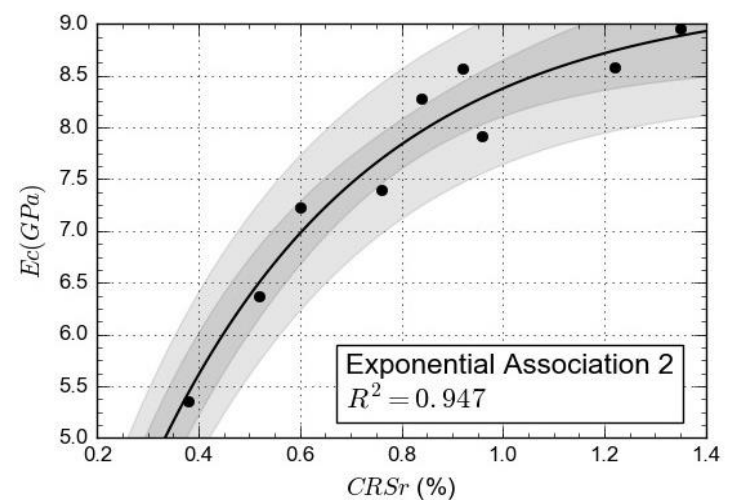

Şekil 12. Beton elastisite modülü ( $\left.E_{c}\right)$-kayaç dayanım katsayısı $\left(\mathrm{CRS}_{\mathrm{r}}\right)$ ilişkisi (Eşitlik 10)

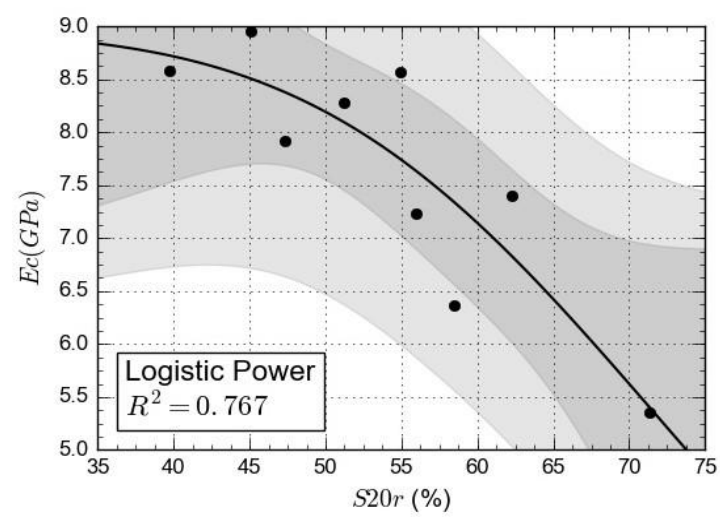

Şekil 13. Beton elastisite modülü $\left(E_{c}\right)$-agrega İsveç kırılganlık değeri $\left(\mathrm{S}_{20 \mathrm{r}}\right)$ ilişkisi (Eşitlik 11)

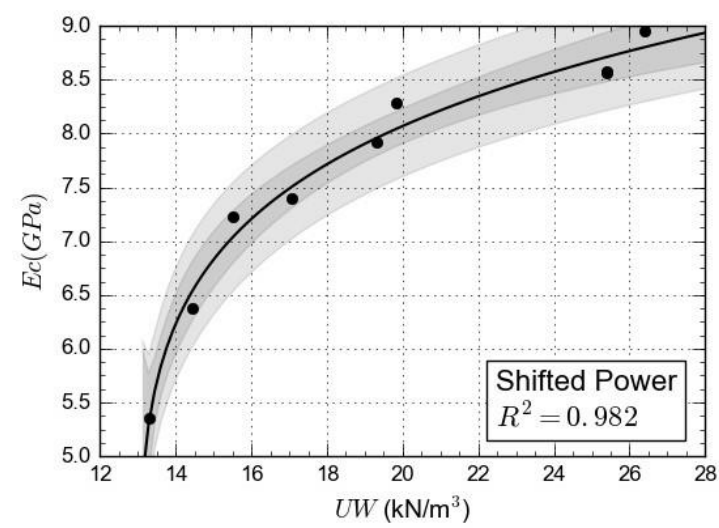

Şekil 14. Beton elastisite modülü $\left(\mathrm{E}_{\mathrm{c}}\right)$-kayaç birim hacim ağırlığı $\left(\mathrm{UW}_{\mathrm{r}}\right)$ ilişkisi (Eşitlik 12) 


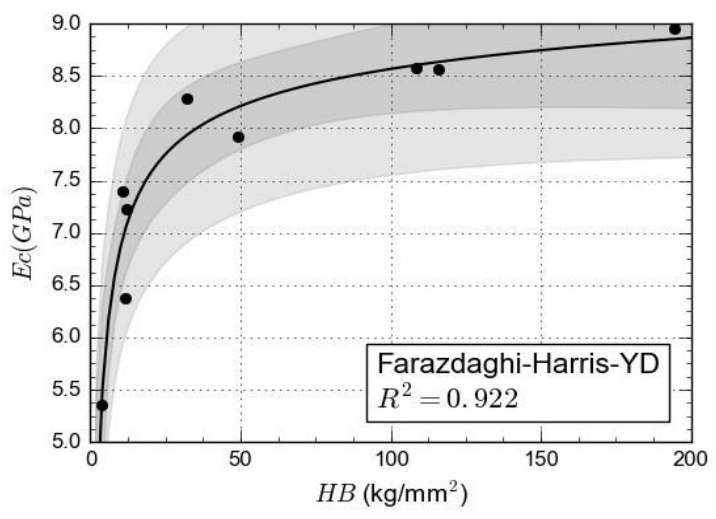

Şekil 15. Beton elastisite modülü $\left(E_{c}\right)$-kayaç brinell sertliği $\left(\mathrm{HB}_{\mathrm{r}}\right)$ ilişkisi (Eşitlik 13)

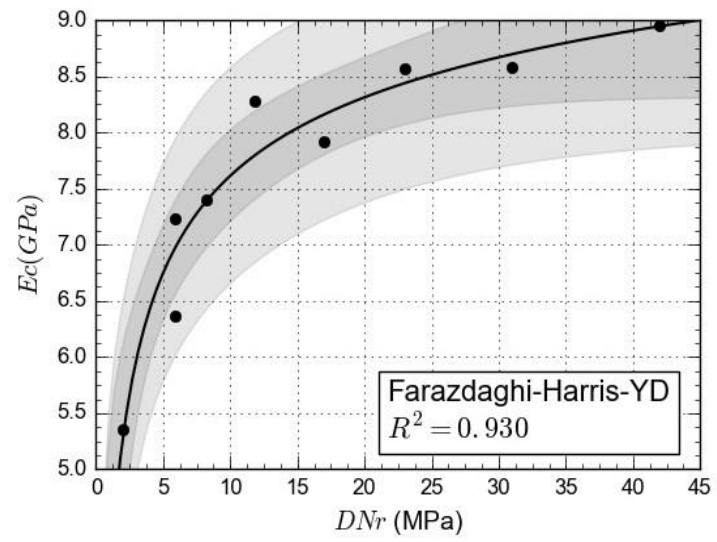

Şekil 16. Beton elastisite modülü $\left(\mathrm{E}_{\mathrm{c}}\right)$-kayaç darbe dayanımı $\left(\mathrm{DN}_{\mathrm{r}}\right)$ ilişkisi (Eşitlik 14)

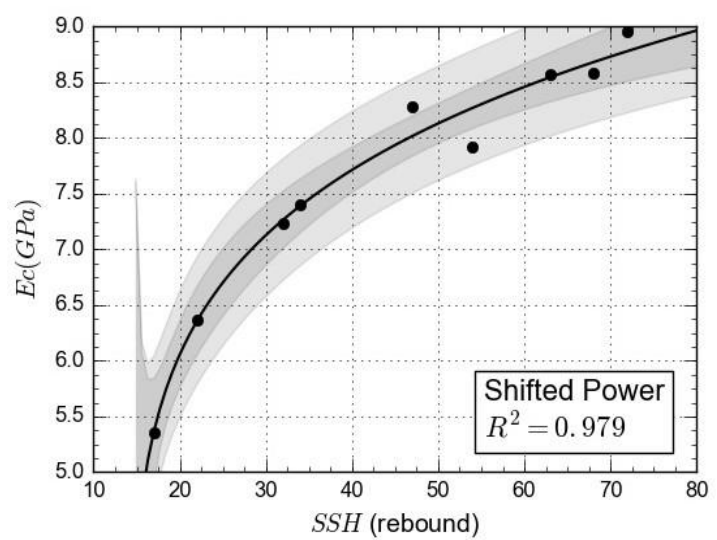

Şekil 17. Beton elastisite modülü $\left(E_{c}\right)-$ kayaç Shore sertliği $\left(\mathrm{SSH}_{\mathrm{r}}\right)$ ilişkisi (Eşitlik 15)

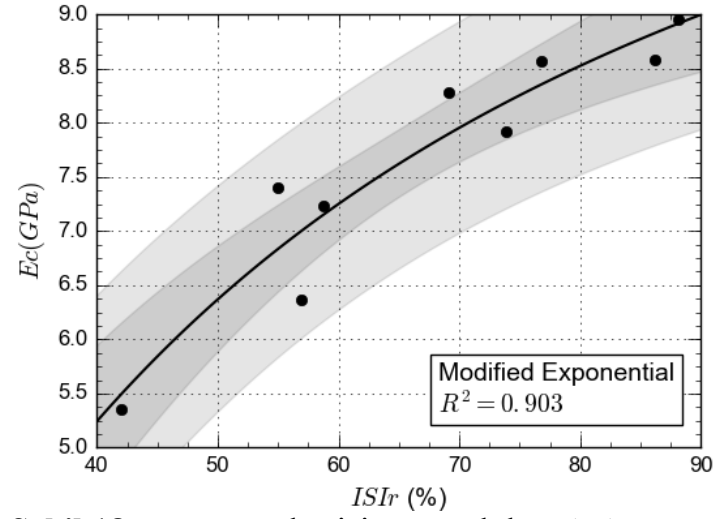

Şekil 18. Beton elastisite modülü $\left(E_{c}\right)$-agrega darbe dayanımı (ISI $)$ ilişkisi (Eşitlik 16)

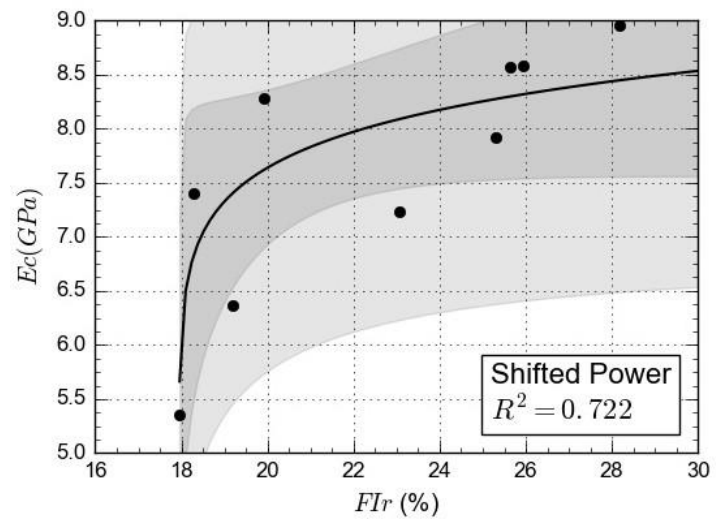

Şekil 19. Beton elastisite modülü $\left(\mathrm{E}_{\mathrm{c}}\right)$-agrega yassılık indeksi $\left(\mathrm{FI}_{\mathrm{r}}\right)$ ilişkisi (Eşitlik 17)

Agrega kayaçlarının elastisite müodülündeki artış, betonların Elastisite modüllerini de artırmıştır. $\mathrm{Bu}$ durum, kaya sertliğinin betonun elastisitesini de etkilediğini gösterir. Bazalt (B), Dolerit (D1-D2) agregalar ile yapılan betonların her biri 28 günlük kür süresinin sonunda üretildikleri kayaçların elastisite modüllerinden daha düşük değerler gösterdiler. Bunun temel nedeni, çimento harcının elastisite modülünün $(7,6 \mathrm{GPa})$ yüksek elastisite değerlerine sahip agrega kayaçlarının elastisite modül değerlerini sınırlamasıdır. Yani agreganın üretildiği kayacın elastisite modül değeri ne kadar yüksek olursa olsun, beton dayanım testlerinde yenilme agrega tanelerini birbirine bağlayan çimento harcında gözlenecektir. Bunun yanısıra, A ve T1 tipi agregalar ile yapılan betonların elastisite 
modülü, ilgili agrega kayaçlarının elastisite modülüne benzerlik göstermektedir.

$\mathrm{Bu}$ durum çimento harcı ve bu agregaların benzer elastisite değerlerine sahip olduğunun bir işaretidir. Buna ek olarak, T2-T5 arası kodlara sahip agregalar ile yapilan betonların elastisite modüllleri, ilgili agrega kayaçlarının elastisite modül değerlerinden daha yüksek değerlere sahiptir. $\mathrm{Bu}$ tür yüksek poroziteye sahip agregaların boşlukları beton karışımı yapılırken çimento partikülleri tarafindan doldurulmakta ve bu şekilde kısmen zayıf dayanıma sahip olan agrega taneleri daha kompozit ve sert bir malzeme haline dönüşmektedir. T2-T5 kodlu agregalarla yapılan betonlarda görülen yüksek Elastisite modülünün diğer bir nedeni ise bağlayıcı vazifesi gören çimento harcının elastisite modül değerinin agregalardan daha yüksek olmasıdır.

Elastisite modülünün tahmin edilebilmesi için yapılan çoklu regresyon çalışmalarında, ortalama sonuçları Çizelge 3 'te özetlenen farklı parametreler kullanılmıştır. Regresyon çalışmalarında üç ve dört bağımsız değişken kullanılmıştır. Elastisite modülünü tahmin etmek için, istatistiksel analizle elde edilebilen en güvenilir ve anlamlı çoklu regresyon denklemleri şunlardır:

$\mathrm{E}_{\mathrm{c}}=0,004 \mathrm{HB}-0,065 \mathrm{FI}-0,031 \mathrm{BSA}+10,289$

$\mathrm{E}_{\mathrm{c}}=0,286 \mathrm{FTS}-0,04 \mathrm{RIHN}+3,945 \mathrm{CRS}+3,837$

$\mathrm{E}_{\mathrm{c}}=0,065 \mathrm{ISI}-0,074 \mathrm{SSH}-0,177 \mathrm{WA}+8,449$

$\mathrm{E}_{\mathrm{c}}=0,722 \mathrm{UPV}+4,061 \mathrm{CRS}-0,033 \mathrm{RIHN}+3,23$

$\mathrm{E}_{\mathrm{c}}=0,014 \mathrm{HB}-0,064 \mathrm{~S}_{20}-0,19 \mathrm{WA}-0,05 \mathrm{CS}+15$

$\mathrm{E}_{\mathrm{c}}=0,022 \mathrm{DN}-0,03 \mathrm{BSA}-0,058 \mathrm{FI}+9,988$

$\mathrm{E}_{\mathrm{c}}=0,008 \mathrm{RIHN}-0,031 \mathrm{BSA}-0,054 \mathrm{FI}+10,025$

$\mathrm{E}_{\mathrm{c}}=0,012 \mathrm{RIHN}-0,034 \mathrm{ISI}-0,037 \mathrm{BSA}+11,22$

$\mathrm{E}_{\mathrm{c}}=0,231 \mathrm{UW}+0,086$ ISI-0,459Is-0,571
Çoklu regresyon denklemlerini doğrulamak için basit regresyonlarda uygulanana benzer şekilde $\mathrm{F}$ ve t-testleri (\%95 güven seviyesi) kullanılmıştır (Çizelge 3). Doğrulamanın daha güçlü olabilmesi için çoklu doğrusallık problemi olup olmadığı da incelenmiştir. Çoklu doğrusallık probleminin göstergesi, 10'dan az olması gereken VIF (varyans enflasyon faktörü) değeridir. $\mathrm{Bu}$ parametre bakımından incelendiğinde Eşitlik 18, 21, 23 ve 24 nolu eşitliklerin çoklu doğrusallık probleminin olmadığı görülecektir. Gözlemlenen ve tahmin edilen $E_{c}$ dağılım diyagramları ve denklemlere ait (Eşitlik 18-26) histogram grafikleri, çoklu regresyonlarda en yüksek katsayıya sahip bazı denklemleri görmek için çizilmiştir (Şekil 20-28). Noktaların her iki bölgede diyagonal çizgiye eşit olarak dağıldığı gerçeği, modellerin güvenilirliğini güçlendirmektedir.

Şekiller detaylı incelendiğinde çoklu tahmin modellerinin basit regresyon denklemlerinden daha güvenilir olduğu görülecektir. Çizelge 3 'ten görülebileceği gibi, çoklu Eşitlik 18-22 arasında verilen regresyonların tümü, varyans analizinde (F-testi) \%95 güven düzeyinde başarılıdır. Benzer bir durum t-testleri için de geçerlidir. Bununla birlikte, Eşitlik 23-26'da bir tane t-değeri tablo değerden düşüktür. $\mathrm{Bu}$ durum, yüksek korelasyon katsayısına sahip olmasına rağmen, kurulan modelde bazı şüphelerin olduğunun bir işaretidir. Çoklu regresyon analizlerinden elde edilen eşitlikler ve bunlara ait güvenirlik analizleri detaylı olarak incelendiğinde $\mathrm{E}_{\mathrm{c}}$ 'nin tahmininde en güvenilir sonuçlar ve yüksek korelasyon katsayıları sırasıyla Eşitlik 18, 22, 20 ve 19'den elde edilmiştir.

Ayrıntılı analizler, çoklu denklemlerin önemli bir bölümünün betonun Elastisite modülünün tahmini için kullanılabileceğini göstermiştir. Çoklu regresyon denklemlerinde birden fazla bağımsız değişken modele girdiğinden, tahmin yetenekleri ve korelasyon katsayıları basit modellerden daha güçlüdür. 
Çizelge 3. Türetilen çoklu regresyon modellerinin geçerliliği (F-testi ve t-testi)

\begin{tabular}{|c|c|c|c|c|c|c|c|c|c|c|c|}
\hline $\begin{array}{c}\text { Eşitlik } \\
\text { no }\end{array}$ & $\begin{array}{l}\text { Bağımsız } \\
\text { değişken }\end{array}$ & $\begin{array}{r}\text { B } \\
\text { (katsay1) }\end{array}$ & $\begin{array}{r}\text { Std. } \\
\text { sapma }\end{array}$ & $\begin{array}{l}\text { Adj. } \\
\mathrm{R}^{2}\end{array}$ & $\begin{array}{r}|t| \\
\text { değeri }\end{array}$ & Sig. & $\begin{array}{r}\mathrm{t} \\
\text { tablo } \\
\end{array}$ & $\begin{array}{r}F \\
\text { değeri }\end{array}$ & Sig. & $\begin{array}{r}F \\
\text { tablo }\end{array}$ & VIF \\
\hline \multirow{4}{*}{18} & Sabit & 10,289 & 0,48 & \multirow{4}{*}{0,993} & 21,36 & 0,00 & \multirow{4}{*}{2,57} & \multirow{4}{*}{356} & \multirow{4}{*}{0,000} & \multirow{4}{*}{5,41} & \\
\hline & BSA & $-0,031$ & 0,00 & & 19,48 & 0,00 & & & & & 2,7 \\
\hline & HB & 0,004 & 0,00 & & 4,01 & 0,01 & & & & & 3,9 \\
\hline & FI & $-0,065$ & 0,02 & & 3,07 & 0,03 & & & & & 5,1 \\
\hline \multirow{4}{*}{19} & Sabit & 3,837 & 0,47 & \multirow{4}{*}{0,937} & 8,14 & 0,00 & \multirow{4}{*}{2,57} & \multirow{4}{*}{41} & & \multirow{4}{*}{5,41} & \\
\hline & FTS & 0,286 & 0,08 & & 3,44 & 0,02 & & & \multirow{3}{*}{0,001} & & 10,2 \\
\hline & RIHN & $-0,042$ & 0,01 & & 3,86 & 0,01 & & & & & 11,0 \\
\hline & CRS & 3,945 & 0,91 & & 4,34 & 0,01 & & & & & 7,6 \\
\hline \multirow{4}{*}{20} & Sabit & 8,449 & 0,95 & \multirow{4}{*}{0,975} & 8,89 & 0,00 & \multirow{4}{*}{2,57} & \multirow{4}{*}{106} & \multirow{4}{*}{0,000} & \multirow{4}{*}{5,41} & \\
\hline & WA & $-0,177$ & 0,03 & & 5,51 & 0,00 & & & & & 21,6 \\
\hline & SSH & $-0,074$ & 0,03 & & 2,93 & 0,03 & & & & & 60,9 \\
\hline & ISI & 0,065 & 0,02 & & 3,22 & 0,02 & & & & & 22,8 \\
\hline \multirow{4}{*}{21} & Sabit & 3,231 & 0,64 & \multirow{4}{*}{0,907} & 5,02 & 0,00 & \multirow{4}{*}{2,57} & \multirow{4}{*}{27} & \multirow{4}{*}{0,002} & \multirow{4}{*}{5,41} & \\
\hline & UPV & 0,722 & 0,28 & & 2,54 & 0,05 & & & & & 6,5 \\
\hline & RIHN & $-0,033$ & 0,01 & & 2,79 & 0,04 & & & & & 8,6 \\
\hline & CRS & 4,061 & 1,10 & & 3,69 & 0,01 & & & & & 7,7 \\
\hline & Sabit & 15,059 & 1,24 & & 12,18 & 0,00 & & & & & \\
\hline & CS & $-0,047$ & 0,01 & & 4,37 & 0,01 & & & & & 94,9 \\
\hline 22 & WA & $-0,188$ & 0,02 & 0,987 & 8,90 & 0,00 & 2,78 & 157 & 0,000 & 6,39 & 18,2 \\
\hline & $\mathrm{S}_{20}$ & $-0,064$ & 0,01 & & 5,04 & 0,01 & & & & & 6,8 \\
\hline & $\mathrm{HB}$ & 0,014 & 0,00 & & 3,95 & 0,02 & & & & & 25,7 \\
\hline & Sabit & 9,988 & 0,54 & & 18,50 & 0,00 & & & & & \\
\hline 23 & BSA & $-0,030$ & 0,00 & 0.080 & 15,08 & 0,00 & 257 & 240 & 0000 & 5.41 & 3,0 \\
\hline 23 & DN & 0,022 & 0,01 & 0,989 & 3,12 & 0,03 & $2,5 /$ & 249 & 0,000 & 5,41 & 4,7 \\
\hline & FI & $-0,058$ & 0,02 & & 2,36 & 0,06 & & & & & 4,9 \\
\hline & Sabit & 10,025 & 0,56 & & 17,92 & 0,00 & & & & & \\
\hline 24 & BSA & $-0,031$ & 0,00 & 0080 & 15,78 & 0,00 & & & 0000 & & 2,8 \\
\hline 24 & RIHN & 0,008 & 0,00 & 0,989 & 3,01 & 0,03 & 2,57 & 238 & 0,000 & 5,41 & 3,5 \\
\hline & FI & $-0,054$ & 0,02 & & 2,20 & 0,08 & & & & & 4,6 \\
\hline & Sabit & 11,220 & 1,17 & & 9,61 & 0,00 & & & & & \\
\hline 25 & BSA & $-0,037$ & 0,00 & 0088 & 8,50 & 0,00 & 257 & 223 & 0000 & 5.41 & 12,8 \\
\hline 25 & RIHN & 0,012 & 0,00 & 0,988 & 2,78 & 0,04 & $2, J /$ & 225 & 0,000 & 5,41 & 9,0 \\
\hline & ISI & $-0,034$ & 0,02 & & 2,06 & 0,09 & & & & & 31,0 \\
\hline & Sabit & $-0,571$ & 1,17 & & 0,49 & 0,65 & & & & & \\
\hline 26 & Is & $-0,459$ & 0,14 & 0.037 & 3,27 & 0,02 & 257 & 40 & 0001 & 5.41 & 16,6 \\
\hline 20 & UW & 0,231 & 0,08 & ונינסי & 3,01 & 0,03 & ו & 40 & 0,001 & J,41 & 13,8 \\
\hline & ISI & 0,086 & 0,02 & & 3,74 & 0,01 & & & & & 11,4 \\
\hline
\end{tabular}
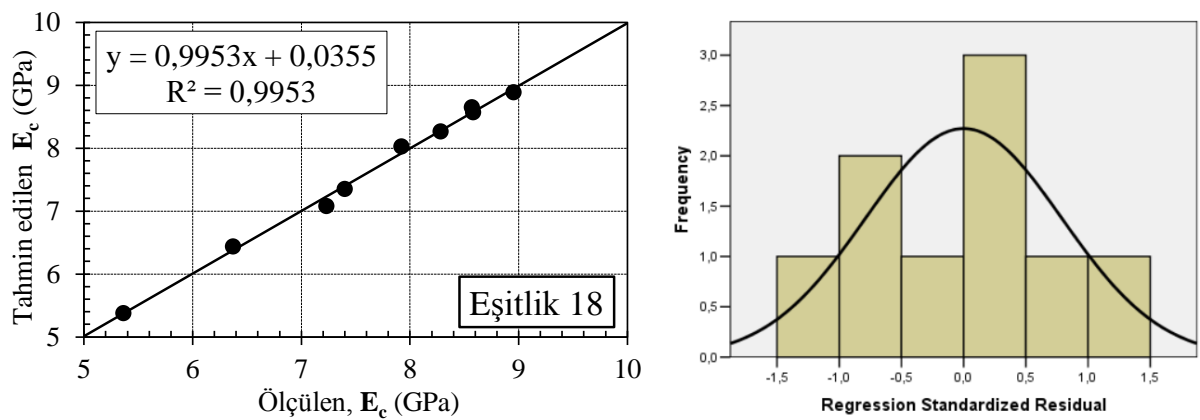

Şekil 20. Ölçülen ve tahmin edilen $\mathrm{E}_{\mathrm{c}}$ değerlerinin karşılaştırılması (Eşitlik 18) 

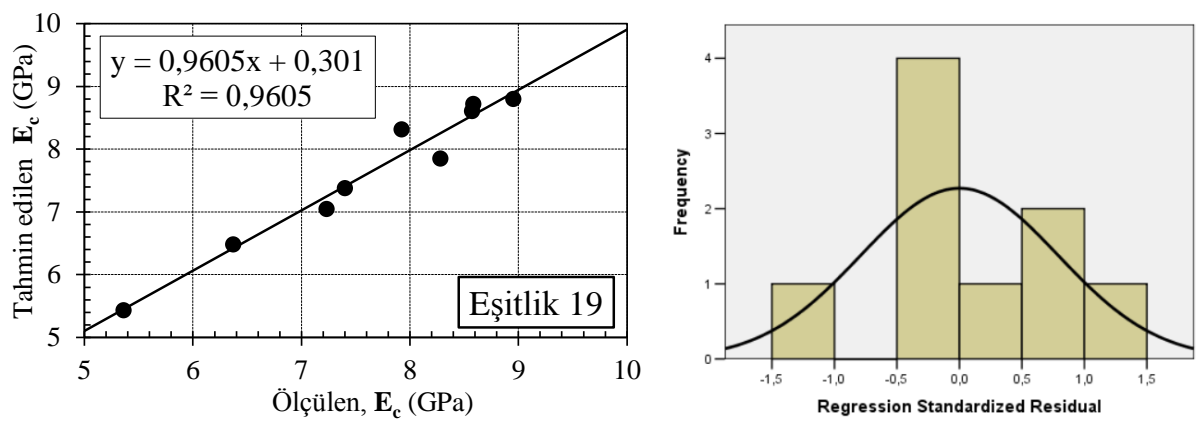

Şekil 21. Ölçülen ve tahmin edilen $E_{c}$ değerlerinin karşılaştırılması (Eşitlik 19)
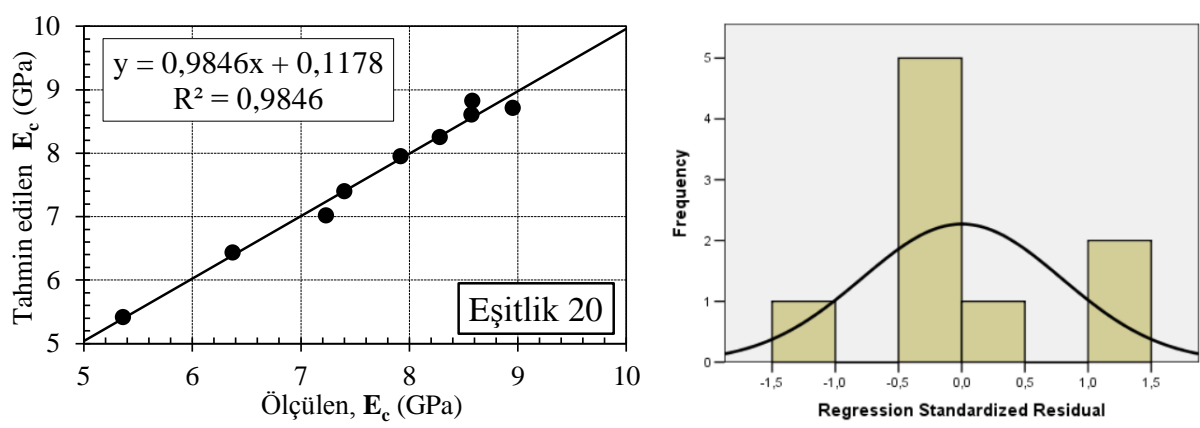

Şekil 22. Ölçülen ve tahmin edilen $\mathrm{E}_{\mathrm{c}}$ değerlerinin karşılaştırılması (Eşitlik 20)
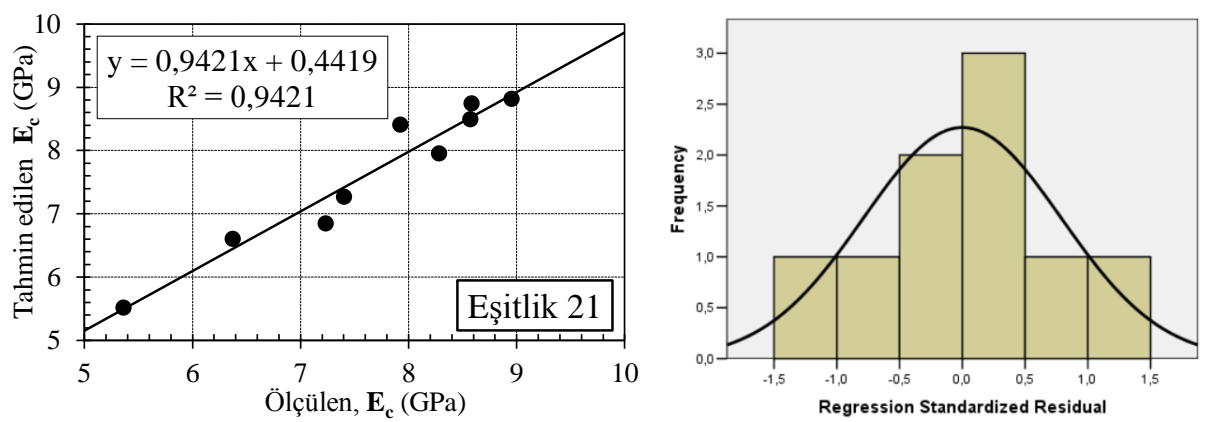

Şekil 23. Ölçülen ve tahmin edilen $\mathrm{E}_{\mathrm{c}}$ değerlerinin karşılaştırılması (Eşitlik 21)
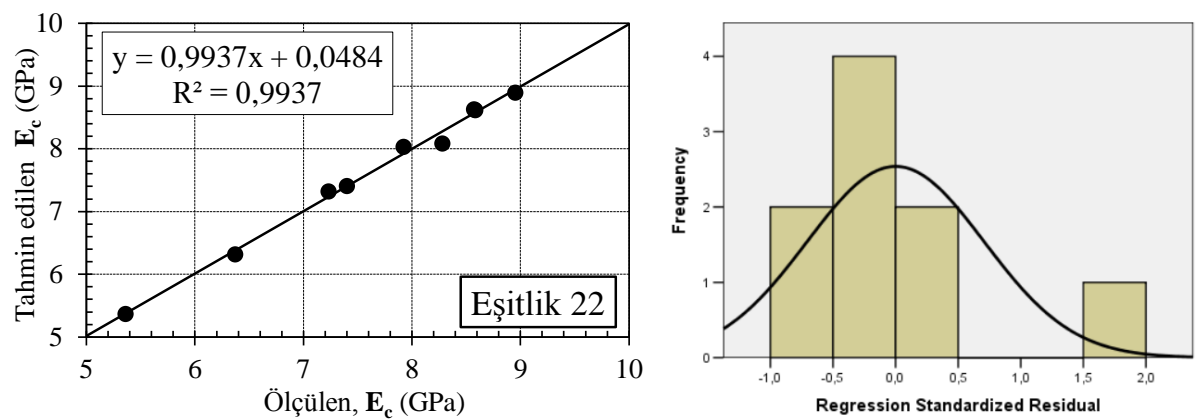

Şekil 24. Ölçülen ve tahmin edilen $\mathrm{E}_{\mathrm{c}}$ değerlerinin karşılaştırılması (Eşitlik 22) 

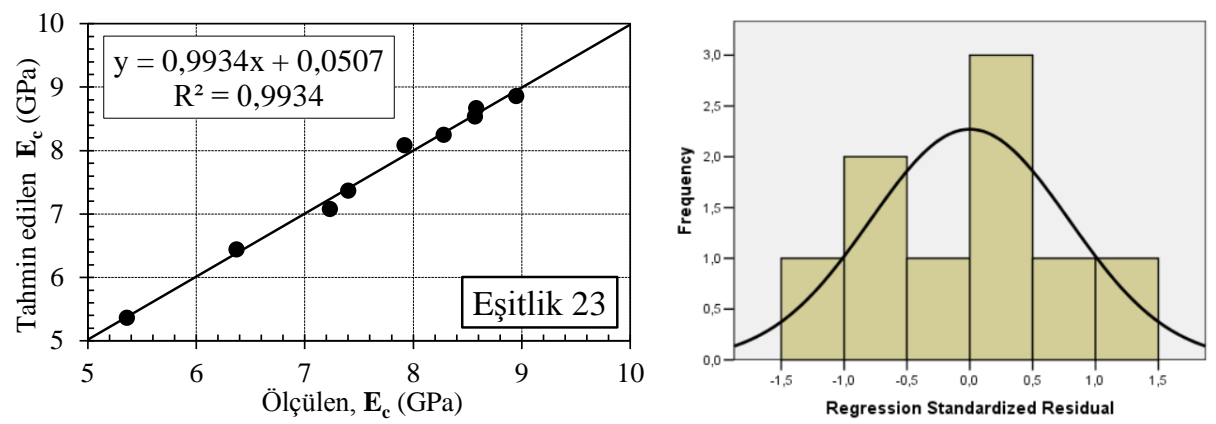

Şekil 25. Ölçülen ve tahmin edilen $\mathrm{E}_{\mathrm{c}}$ değerlerinin karşılaştırılması (Eşitlik 23)
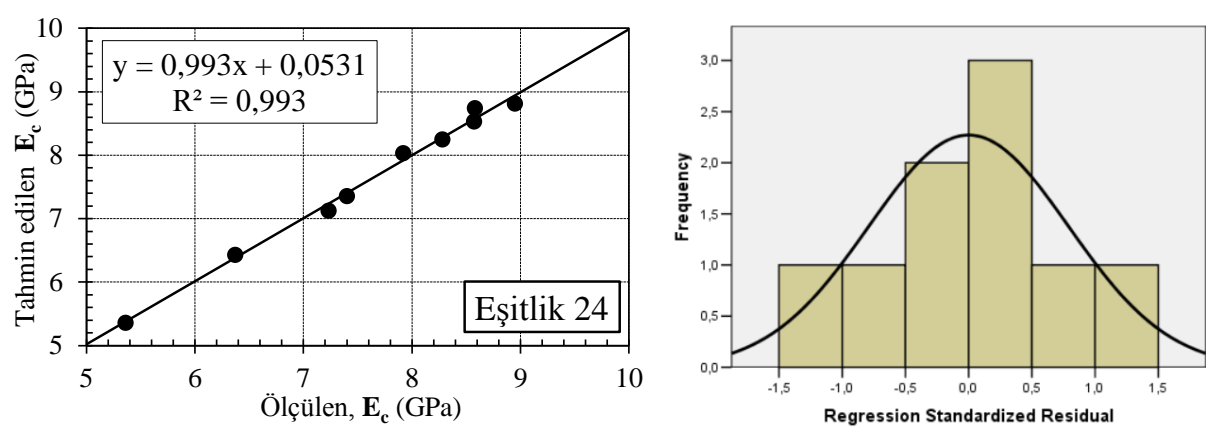

Şekil 26. Ölçülen ve tahmin edilen $\mathrm{E}_{\mathrm{c}}$ değerlerinin karşılaştırılması (Eşitlik 24)
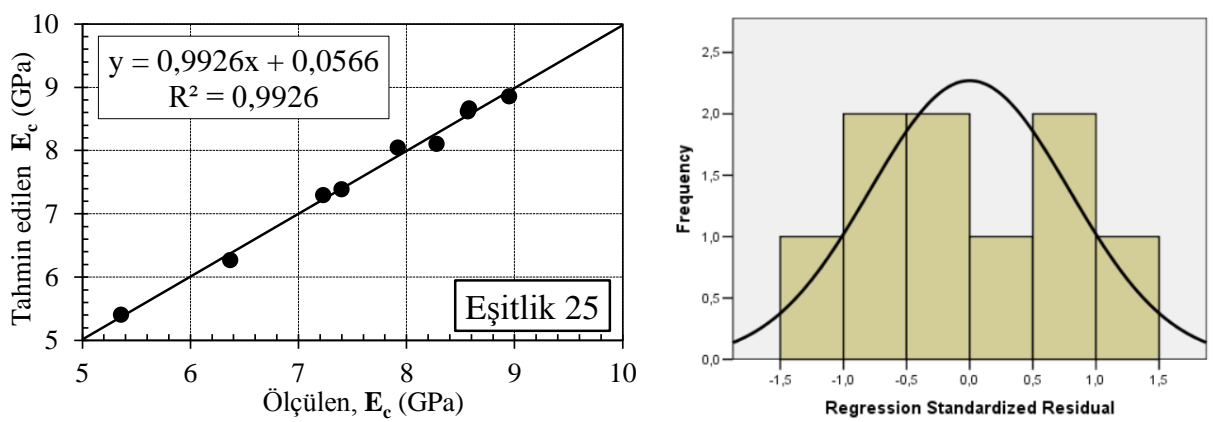

Şekil 27. Ölçülen ve tahmin edilen $\mathrm{E}_{\mathrm{c}}$ değerlerinin karşılaştırılması (Eşitlik 25)
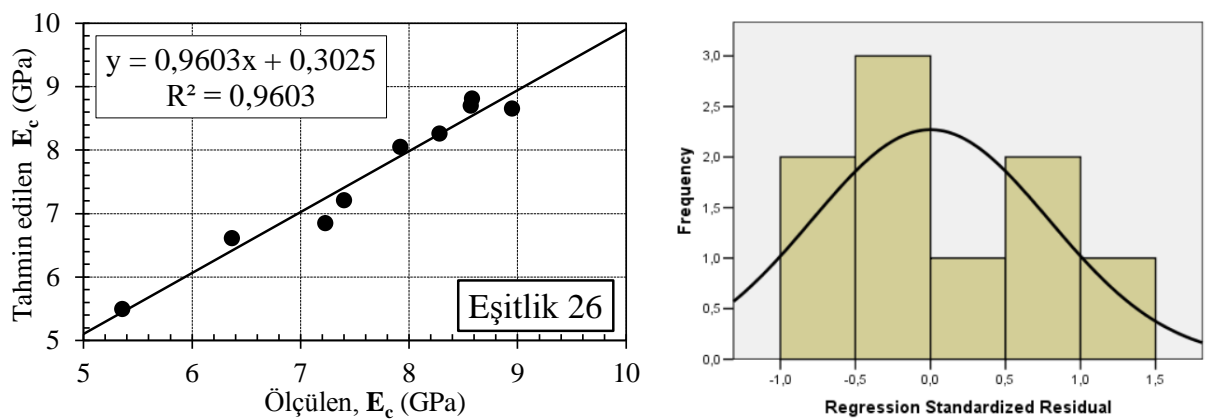

Şekil 28. Ölçülen ve tahmin edilen $\mathrm{E}_{\mathrm{c}}$ değerlerinin karşılaştırılması (Eşitlik 26) 


\section{SONUÇLAR}

$\mathrm{Bu}$ çalışma, tespiti zor ve zaman alıcı olan beton elastisite modülünün, o betonun temel bileşeni olan ve kismen daha basit ve kolay uygulanabilir agrega (kayaç) özelliklerinden tahmin edilebilmesine yöneliktir. Çalışmada, volkanik yüzey kayaçlarından elde edilen agregalar ile üretilen betonların elastisite modülleri ile bu agrega/kayaçların bazı mühendislik özellikleri arasındaki korelasyonlar incelenmeiştir ve çoklubasit regresyon analizlerinden çıkarılan sonuçlar aşağıdaki maddelerde özetlenmiştir.

- Denklemler F ve t-testleri ile doğrulanmıştır. Ölçülen ve tahmin edilen sonuçlar arasında \%94,2-\%99,5 aralığında değişen yüksek korelasyon katsayılı denklemler elde edilmiş ve bu durum da $E_{c}$ parametresinin tahmin edilmesinde güvenilir sonuçlar ortaya konulmuştur.

- Kayaç/agrega özellikleri ile ilgili birden fazla test verisi varsa, çoklu regresyon teknikleri kullanılarak üretilen denklemler $\mathrm{E}_{\mathrm{c}}$ 'yi tahmin etmek için kullanılabilir. İki parametrenin korelasyonundan elde edilen basit regresyon denklemleri, tahmini amaçlar için kullanıldığında yeterince pratik ve güvenilirdir. Bununla birlikte, daha kesin tahmin için iki veya daha fazla bağımsı değişkenin kullanıldığı çoklu regresyon denklemleri kullanılabilir.

- Sonuç olarak, türetilen bu denklemler, güvenilir ve anlamlı ilişkileri temsil eder, ancak farklı karışım koşullarına sahip betonlarda kullanıldığında özen gösterilmelidir. $\mathrm{Bu}$ makale kapsamında değerlendirilen parametreler, farklı su/çimento oranında ya da farklı agrega tipleri ile üretilen betonlar için de değerlendirilebilir.

- Betonun basınç dayanımı ve Elastisite modülü gibi temel mühendislik özellikleri belirlenmesi zaman alıcı ve zor olan önemli parametrelerdir. Öte taraftan çalışma kapsamında gerçekleştirilen agrega/kayaç deneylerinin büyük bir bölümü oldukça basit test ekipmanına, oldukça az miktarda deney numunesine ihtiyaç duyulan testlerdir. Dolayısı ile literatürde çok rastlanmayan özellikler taşıyan bu çalışmanın ortaya koyduğu eşitlikler, betonun elastisite modülünün belirlenmesinin çok mümkün olmadığı durumlarda özellikle tahmin amaçlı olarak güvenilir bir şekilde kullanılabilecektir.

\section{KAYNAKLAR}

1. Mehtra, P.K., 1986. Concrete: Structure, Properties and Materials. $2^{\text {th }}$ Ed. Englewood Cliffs, NJ: Prentice-Hall Inc.

2. Neville, A.M., 1995. Properties of Concrete, $4^{\text {th }}$ Ed. London: Longman Group UK Limited Press.

3. ACI Committee 221, 2001. Guide for Use of Normal Weight Aggregate in Concrete, ACI Manual of Concrete Practice: Part 1. Farmington Hills (MI).

4. Neville, A.M., 1981. Properties of Concrete, $3^{\text {rd }}$ Ed., Longman Scientific, 287, London.

5. Zia, P., 1994. International Workshop on High Performance Concrete, ACI SP-159, 215-223, Detroit.

6. Aitcin, P.C., Mehta, P.K., 1990. Effect of Coarse-Aggregate Characteristics on Mechanical Properties of High-Strength Concrete, ACI Mater J, 87, 103-107.

7. De Larrard, F., Belloc, A., 1992. Are Small Aggregates Really Better for Making HighStrength Concrete? Cem Concr Aggregates 14: 62-66.

8. Kaplan, M.G., 1986. Ultrasonic Pulse Velocity, Dynamic Modulus of Elasticity, Poisson Ratio, and Strength of Concrete Made With Thirteen Different Coarse Aggregates, RILEM Bull., No.1, New Series, 17-28.

9. Davis, D.E., Alexander, M.G., 1989. Properties of Aggregate in Concrete (Part 1), Hippo Quarries Technical Publication Sandton, Hippo Quarrie, South Africa.

10. Özturan, T., Çeçen, C., 1997. Effect of Coarse Aggregate Type on Mechanical Properties of Concretes With Different Strengths, Cement and Concr Res 27, 165-170. 
11. Beshr, H., Almusallam, A.A., Maslehuddin, M., 2003. Effect of Coarse Aggregate Quality on the Mechanical Properties of High Strength Concrete. Constuction Building Material, 17, 97-103.

12.Zhou, F.P., Lydon, F.D., Barr, B.I.G., 1995. Effect of Coarse Aggregate on Elastic Modulus and Compressive Strength of High Performance Concrete. Cem. Concr. Res. 25, 177-186.

13. Wu, K.R., Chen, B., Yao, W., Zhang, D., 2001. Effect of Coarse Aggregate Type on Mechanical Properties of High-Performance Concrete. Cem. Concr. Res. 31, 1421-1425.

14. Kılıç, A., Atiş, C.D., Teymen, A., Karahan, O., Özcan, F., Bilim, C., Özdemir, M., 2008. The Influence of Aggregate Type on the Strength and Abrasion Resistance of High Strength Concrete. Cem. Concr. Compos. 30, 290-296.

15. ISRM, 1981. Rock Characterization, Testing and Monitoring. In: Brown Et, Editor. ISRM (International Society for Rock Mechanics) Suggested Methods. Oxford: Pergamon.

16. Güneyli, H., Yapıcı, N., Karahan, S., 2016. Doğal Anhidritin Beton Bileşeni Olarak Kullanımı. Çukurova Üniversitesi Mühendislik Mimarlık Fakültesi Dergisi, 31 (2), 7-15.

17. Kilic, A.M., Kilic, Ö., Keskin, M.O., 2010. The Effect of the Rock Type Forming the Aggregate in Lightweight Polymer Concrete on Compressive and Flexural Tensile Strength. Scientific Research and Essays, 5 (15), 1986-1992. 